\title{
CONFERÊNCIAS
}

\section{HEMORRAGIA CEREBRAL. NOVOS CONCEITOS DE PATOGENIA, DIAGNÓSTICO E TRATAMENTO}

\author{
Diogo Fuptado*
}

E' grande a importância social do insulto apoplético em garal. Volhard afirma que na Alemanha, em 1939, sessenta mil casos de morte foram devidos a insulto apoplético; em Portugal, nós próprios pudemos computar de seis a sele mil o número de mortes anuais devidas à apoplexia. Esta causa de mortalidade figura hoje, na maior parte dos países, em terceiro lugar, seguindo imediatamente as doenças cardiovasculares $\mathrm{e}$ as neoplasias malignas $\mathrm{e}$ antecedendo a tuberculose.

$O$ insulto apoplético é mais freqüente do que qualquer outra doença do sistema nervoso, e. não constitui apenas uma das mais importantes causas de morte, como também uma das principais causas de invalidez pelo grande número de seqüelas paralíticas que após si deixa.

As principais causas do insulto apoplético, estado mórbido que traduz a interrupção da circulação sangüínea do cérebro, são: a hemorragia cere?.ral; o amolecimento, por trombose e oclusão dos vasos encefálicos; a embolia dêstes vasos. Existem, evidentemente, outras causas de insulto apoplético; estão neste caso, por exemplo, as hemorragias subaracnóideas e certas hemorragias ocorridas dentro dos tumores. Mas as suas principais causas são constituídas por aquelas três entidades mórbidas. Delas, duas avultam: a hemorragia cerebral e o amolecimento.

Uns autores computam o amolecimento mais freqüente do que a hemorragia; outros têm ponto de vista contrário. De nossa estatística temos podido verificar que hemorragias e tromboses com amolecimento constituem número sensivelmente igual de casos de insulto apoplético. Trataremos, aqui, da hemorragia cerebral.

$\mathrm{Na}$ impossibilidade de expor tôda a sua patologia, patogenia e terapêutica, vamos limitar-nos a algumas questões mais momentosas, aquelas em que tenha havido evolução ou progresso. Assim, trataremos sucessivamente da patogenia da hemorragia cerebral, faremos depois algumas con-

Conferência pronunciada no Serviço de Neurologia da Fac. Med. da Univ. de São Paulo (Prof. A. Tolosa) em 11 setembro 1952.

* Professor da Faculdade de Medicina de Lisboa. Director do Serviço de Neurologia dos Hospitais Civis de Lisbea. 
siderações acêrca do seu diagnóstico diferencial, para terminarmos por abordar o seu estudo terapêutico.

Durante muitos anos se adoptou um conceito patogénico mecânico e simplista de hemorragia cerebral. Esta era explicada paradoxalmente pela associação de duas doutrinas opostas, ambas elas erradas. A primeira era a doutrina francêsa, oriunda de Charcot e Bouchard, a qual atribuía a hemorrag.a cerebral à rotura de aneurismas múltiplos de origem inflamatória, tendo a sua sede num dos ramos profundos da artéria sílvica, ramo êste que mereceu de Charcot o nome de artéria da hemorragia cerebral. Pelo contrário, a segunda teoria, de autoria de Virchow e de Kölliker, procurava explicar a hemorragia cerebral pela rotura das paredes vasculares de um vaso cerebral alterado por uma suposta arteriosclerose.

Durante anos os tratadistas oscilaram entre estas duas hipóteses patogénicas para acabarem por adoptar a teoria mista, que explica a hemorragia cerebral pela rotura dum único aneurisma, mas de etiologia arteriosclerótica. Assim, de duas teorias opostas, nenhuma delas seguramente correspondendo à realidade, resultou uma terceira doutrina, mais falsa provàvelmente do que as duas iniciais.

$O$ conceito de hemorragia cerebral evolucionou profundamente e para expor esta evolução é preferível que partamos da concepção primitiva para a doutrina actual. Começaremos por estabelecer esta fazendo a contestação sistemática, facto por facto, da hipótese antiga. Partiremos de factos negativos para estabelecermos seguidamente factos positivos, da conjuncção dos quais resultará lògicamente a doutrina actual, explicativa do fenómeno da hemorragia cerebral.

Em primeiro lugar há a afirmação de que não existem aneurismas. Contràriamente à teoria corrente, a hemorragia cerebral não é devida à rotura de um aneurisma. Os trabalhos experimentais de Fick e Ellis, de Globus e de Strauss e sobretudo o trabalho de Schwartz provaram cabalmente que os vasos cerebrais dos falecidos por hemorragia não apresentam formações aneurismáticas. Em casos excepcionais encontrou Schwartz hematomas intramurais, capazes de simularem aneurismas; na realidade, porém, não se trata de aneurismas, mas de falsos aneurismas. Assim, fica contestada a primeira parte da teoria referida.

Em segundo lugar, não há roturas sem aneurisma. Hiller, Beitz, Boeck e ouiros pretenderam que, mesmo quando não existisse aneurisma, a heniorragia era devida à rotura larga dum vaso do cérebro. Schwartz contesta êste facto que, de resto, a maioria das autópsias contesta também. Quem autopsia um cérebro com hemorragia, raramente encontra grande rotura dum vaso; é êste um facto paradoxal, mas de comum observação. Schwartz vai mais longe afirmando que o tecido cerebral não é repelido, como sucederia se existisse uma verdadeira hemorragia, isto é, um hematorna intracerebral, mas sim que êle é infiltrado pelo sangue, encontrando-se no foco ainda a própria estructura trabecular da substância cerebral. Só existiria rotura verdadeira nos casos raros de hematoma intracerebral de gran- 
de e crescente volume. A hemorragia cerebral comum não seria, pois, devida à rotura, mesmo ocorrida sem aneurisma.

Recentemente, tende-se a voltar à doutrina de rotura, agora já não de rotura dum vaso importante, mas pequenos fenómenos de "rhexis" ocorridos nos vasos de menos importância. Adiante voltarei a ocupar-me dêste aspecto da doutrina actual.

Em terceiro lugar, um número muito elevado de hemorragias cerebrais dá-se em vasos reconhecidos como sãos, e assim fica contestada outra parte da teoria de que partimos, a de que os vasos teriam sido arteriosclerose. Citam-se, como exemplos clássicos, a apoplexia do saturnismo, a da eclâmpsia (cêrca de $40 \%$ dos casos de eclâmpsia morrem de hemorragia cerebral), a da enxaqueca e até a que às vêzes aparece após os ataques epilépticos. Em todos êstes casos, com vasos inteiramente sãos, e tratando-se de reacções de pura natureza vasomotora, é possível o aparecimento de uma hemorragia cerebral que conduz à morte. $O$ exemplo rnais curioso, talvez, dêste género, é o da Spät-Apoplexie ou apoplexia traumática de Bollinger: trata-se de afecção descrita há muito, na qual, após um traumatismo cerebral de relativamente pouca importância, tempos depois, semanas, às vêzes meses, se estabelece no foco atingido pela contusão cerebral ou na sua vizinhança, uma hemorragia que leva o paciente à morte.

Foi possivel, durante a última guerra, observar numerosos casos dêste género. Dêles se ocupou Jewsbury, que pôde demonstrar que, em tais casos, o traumatismo provoca um foco de contusão, necrose parenquimatosa cerebral, que fica latente e que mais tarde vai provocar, por um mecanismo vasomotor, uma angionecrose seguida de hemorragia; assim, a presença dum foco de contusão vai produzir na vizinhança, por um mecanismo reflexo vasomotor, um foco de hemorragia cerebral.

Ainda sob êste aspecto convém discutir se existem realmente lesões específicas dos vasos nas regiões atingidas pela hemorragia cerebral.

Não me ocuparei de numerosos tipos de lesões, hoje mais ou menos postas de parte. Limitarei as minhas referências à hialinose descrita por Scholtz, a qual corresponde sensivelmente a outras alterações encontradas nos vasos atingịdos de hemorragia cerebral; são consideradas idênticas à hialinose de Scholtz, a alteração plasmática de $W^{\prime}$ olff, a angionecrose de Beitzke e de Spatz, e outras alterações que eventualmente têm sido descritas.

A hialinose de Scholtz consiste no aparecimento de uma substância homogénea de localização subendotelial nos vasos situados no foco da hemorragia. A alteração não se limita, porém, à túnica interna; existe simultâneamente uma necrose da média com destruição das fibras elásticas, e, nas formas mais adiantadas, uma verdadeira homogenização da parede do vaso. Esta substância homogénea que se deposita nos vasos lesados toma difusamente os corantes da gordura e cora-se de amarelo acastanhado pelo van Gieson. Parece tratar-se de uma substância de origem dege- 
nerativa, possivelmente resultante da alteração das proteínas, e próxima parente da substância amilóide.

Spatz explica êste aspecto alterado dos vasos como uma conseqüência das modificações vasomotoras. Consecutivamente a sucessivas constriç̧ões vasculares, os vasos da própria parede do vaso, isto é, os vasa vasorum, sofrem um processo obliterativo do qual resulta uma necrose parietal secundária. A esta origem vasomotora de tal aspecto alterado dos vasos, juntar-se-ia provàvelmente uma alteração centrípeta, isto é, uma modificação do vaso resultante da alteração do tecido cerebral circundante. Em qualquer caso, o processo de hialinose encontrado, de resto não constantemente, nas paredes dos vasos próximos do foco hemorrágico, não parece ser a causa imediata da própria hemorragia, mas antes talvez a conseqiiência dum mecanismo patogénico que conduz a esta.

O papel da arteriosclerose não merece larga discussão, a despeito da doutrina clássica lhe atribuir tanta importância na causa da hemorragia. A arteriosclerose, tornando os vasos mais sólidos, tornando esclerótica a túnica muscular da média, contribui não para enfraquecer os vasos cerebrais, mas, pelo contrário, para os reforçar. Na realidade, a arteriosclerose é antes uma mecanismo de defesa contra a hemorragia cerebral e é a sua existência a causa de que nos velhos a hemorragia seja muito menos freqüente do que o amolecimento.

Nos últimos anos tem-se descrito uma outra afecção vascular da circulação cerebral - a arteriolopatia hipertensiva - cujo papel merece também referência. Produzida experimentalmente por Köeys e Goldblatt nos seus animais com hipertonia, por alteração do pedículo renal, esta lesão consiste numa degenerescência hialina, sem hipcrplasia da íntimá e com integridade da média. Scheinker afirma tê-la encontrado nos vasos cerebrais do homem, em casos de hemorragia cerebral. Na realidade, a arteriolopatia hipertensiva merece ser considerada, não como um factor predisponente para a hemorragia, mas também como um mecanismo defensivo contra esta. Conseqüência da hipertensão arterial, a arteriolıpatia de Keys e Goldblatt não parece ser um mecanismo de debilitação parietal predisponente para a hemorragia.

Outro facto que deve ser considerado na refutação da teoria clássica é a circunstância do foco apoplético não ser único. Em muitos casos, além do foco principal, existem outros focos acessórios. Circunstância curiosa e difìcilmente explicável, êstes focos são mu tas vêzes simétricos. Esta multiplicidade de focos não pode ser explicada pela doença local dum vaso com arteriosclerose, disposto à rotura, como pretendia a doutrina clássica.

Mas a multiplicidade não se limita aos grandes focos. Em tôrno do foco principal da hemorragia cerebral existem pequenos focos acessórios dispostos em coroa, cuja patogenia também a doutrina clássica não parecia suficiente para explicar. Estes pequenos focos são explicados por Schwartz como resultantes duma transudação simultânea de todo o terri- 
tório vascular atingido. Para Schwartz, a árvore vascular funciona como unidade topística, com uma reacção total, e os pequenos focos existentes além do foco principal seriam a expresssão desta reação duma unidade topística.

Stemler, que não aceita esta doutrina, supõe os pequenos focos em questão resultantes da acção traumática do foco principal. Declman e nós próprios, tentamos a sua provocação injectando em cérebros de animais sangue dos mesmos animais, criando assim uma forma experimental de hematoma intracerebral. Pudemos ver, tal como sucedeu a Declman. que também em tôrno dêstes focos, ao fim de algumas horas, se produzem pequenos focos hemorrágicos dispostos em coroa. Trata-se assim, a nesso ver, duma acção traumática directa do foco principal, o qual, produzindo reflexos vasomotores, vai criar à sua volta outros focos secundários de hemorragia. O fenómeno parece, portanto, muito semelhante ao da SpätApoplexie, cuja patogenia explicativa foi precisamente esta.

Um outro facto que a doutrina clássica não é capaz de explicar, é o da sede preferencial da hemorragia cerebral. Como se sabe, esta atinge as ramificações terminais de certas arteríolas dos ramos profundos da cerebral média, dispondo-se numa região a que Schwartz chama "putâminocápsulo-claustral". Por que motivo são mais estreitos tais ramos vasculares à hemorragia cerebral, do que a restante circulação do sangue? Para tal têm sido dadas explicações de ordem mecânica. que me parecem bastante artificiais.

Tentou-se explicar, admitindo que os ramos profundos da sílvica se encontravam numa direcção quase rectilínea com a própria direç̧ão da carótida. Assim, a propagação da onda pulsátil vinda da aorta, far-se-ia ao longo da carótida e atingiria mais directamente êstes ramos profundos e proximais da média, os quais sofreriam, com mais intensidade do que a restante circulação cerebral, as variações da tensão cerebral. Na realidade, existem objecções fundamentais e incontestáveis de tal doutrina. São elas, principalmente, a circunstância de que as hemorragias cerebrais ocorridas em esiados mórbidos não acompanhados de hipertensão, se dão na mesma região; é o que sucede com as hemorragias cerebrais dos envenenamentos pelo óxido de carbono, pelo ácido cianídrico e pela morfina.

Uma explicação puramente mecânica não serve para as hemorragias dêste tipo especial, nas quais não existem variações da tensão arterial. Também aqui a Medicina experimental forneceu os dados necessários para explicar o fenómeno permitindo admitir que a sede da hemorragia cerebral está possìvelmente em relação com a avidez da referida zona para o exigénio.

Realmente, estudos feitos pela técnica de Barcroft Warburg permitiram ver que, sendo o cérebro o órgão que mais oxigénio consome no organismo, é a sua substância cinzenta a parte que, por sua vez, mais cxigénio necessita dentro da substância cerebral. E' provável que esta avidez de oxigénio esteja em relação com o conteúdo de ferro existente na referida zona. Em qualquer caso, parece que a explicação da sede habi- 
tual e preferencial da hemorragia cerebral não residirá em factôres mecânicos de pressão, mas na avidez de determinada região para o oxigénio circulatório.

Se, perante os factos referidos, excluímos a hemorragia cerebral resultante duma rotura, tal como pretendia à doutrina clássica, como poderemos conceber então a sua patogenia? Múltiplas são as teorias que lêm sido propostas e não seria possível revê-las tôdas.

Quero fazer menção apenas a dois autores pelo papel fundamental que tiveram na situação actual dos nossos conceitos sôbre a hemorrugia cerebral. O primeiro é Rosenblath que, expondo a doutrina dos fermentos nefrogénicos, admitiu, pela primeira vez, que a hemorragia não seria conseqüência da doença do próprio vaso, partindo de dentro para fora, mas sim duma alteração parenquimatosa, que se repercutiria secundàriamente sôbre o vaso. O outro autor que desejo mencionar é Schwartz, que produziu, no capítulo da patogenia da hemorragia cerebral, obra notável que prossegue ainda hoje em Istambul onde é professor.

Patentes os dados negativos da refutação da teoria em questão, é altura de serem apresentados alguns dados positivos, justamente aquêles sôbre os quais assenta nossa actual concepção.

Em primeiro lugar, quero ocupar-me do papel da hipertensão arterial. E' clássico dizer que a hemorragia cerebral é o insulto apop!ético dos hipertensos. Desde que, há 50 anos, se começou medindo sistemàticamente a tensão arterial, é um facto verificado por todos os clínicos, o de que o insulto apoplético hemorrágico é mais freqüente nos hipertensos do que nos normotensos. Qual a relação desta hipertensão com o fenómeno hemorrágico, desde o momento em que pomos de parte a hemorragia por rotura dum vaso doente pela acção do próprio aumento da pressão?

A hipertensão mantém, para a doutrina actual, o mesmo papel importante que mantinha para a doutrina da rotura; simplesmente, as suas variações é que funcionam como excitaçōes determinantes das modificações funcionais. Não é o próprio valor constante da tensão, que força um vaso doente; são as suas variações repetidas, bem conhecidas em todos os hipertensos, por excelência vasolábeis, que trazem como conseqüência modificações funcionais na própria circulação cerebral. Sabido como é, que a hemorragia atinge principalmente individuos de constituição vasolábil, aquilo a que Hochrein chamou a constituição neuro-circulatória, e Tchetverikoff o "morbus vaso-espasticus", compreendem-se fàcilmente os efeitos nocivos destas incessantes variações da tensão arterial sôbre a vasomotilidade da circulação cerebral.

Outro ponto de que me quero ocupar é o dos aspectos morfológicos dêstes fenómenos funcionais dos territórios vasculares cerebrais.

Devemos a Ricker o conhecimento da teoria geral dos fenómenos vasomotores ocorridos após os estímulos a que são submetidos os vasos. Para a circulação em geral, aceita Ricker que um estímulo de pequena intensidade tem como conseqüência uma vasodilatação fugaz. Se a intensidade 
do estímulo aumenta, a conseqüência na fase seguinte será, não uma vaso. dilatação, mas uma vasoconstriç̧ão. Sob uma intensidade máxima, o efeito é de novo diferente; existe então o que chama Ricker uma vasoparalisia, constituída por duas fases: uma fase pré-estática, com eritrodiapedese e ainda reversível, e uma fase final de estase, com diapedese maciça e alteração secundária definitiva da parede vascular. Esta doutrina de Ricker, de largo alcance patológico geral, foi aplicada aos fenómenos da circulação cerebral por Schwartz. Para êste autor os vasos cerebrais reagiriam como unidades funcionais topísticas e, consoante as intensidades dos estímulos a que são sujeitos, teriam lugar o aparecimento de vasodilatação, vasoconstricção e vasoparalisia. Os estímulos que provocariam incessantemente estas modificações seriam justamente as variações da tensão arterial ocorridas dentro dos próprios vasos. Seriam estas as causas de sucessivas modificações no sentido da vasoconstricção e da vasodilatação, cujo papel adiante veremos na patogenia da hemorragia.

Um outro grupo de factos, no domínio das aquisições positivas de fundamentos patogénicos da hemorragia cerebral que convém mencionar, são os que se referem ao papel das veias.

Foram surgindo nos últimos anos dúvidas acêrca da origem arterial ou venosa da hemorragia cerebral. Aring e Scheinker defendem recentemente a possibilidade duma patogenia venosa do insulto hemorrágico. Com efeito, um número apreciável de argumentos se nos deparam em favor da possibilidade de uma origem venosa: em primeiro lugar, a própria fraqueza das veias cerebrais, pois, ao passo que as arteríolas dispõem de túnica média elástica, as veias não têm fibras elásticas na sua túnica média e são mais frágeis do que as artérias; em segundo lugar, o espessamento das arteríolas em conseqüência da doença hipertensiva, a qual, constituindo um mecanismo de defesa, se não encontra nas veias; em terceiro lugar, experiências várias mostram que as veias cerebrais do homem respondem também às alterações funcionais das arteríolas. Nos nossos estudos sôbre a acção vasodilatadora cerebral do ácido nicotínico e dos seus derivados, pudemos demonstrar que as variações de calibre provocadas pelos dilatadores nicotínicos sôbre as arteríolas, eram acompanhadas igualmente duma modificação, no mesmo sentido, do calibre das veias.

Outro facto seria a explicação da preferência da hemorragia cerebral pela região dos núcleos centrais. Nesta região, passam exactamente as grandes veias anastomóticas do cérebro e seria, portanto, a origem venosa das hemorragias uma possível explicação desta sede. $O$ facto da localização da hemorragia cerebral não corresponder ao território de distribuição duma arteríola, facto muitas vêzes citado como óbice à doutrina da rotura vascular, poderia também ser evocado como argumento a favor da origem venosa destas hemorragias.

Por último, a própria diferença da idade em relação à trombose cerebral, é outro argumento clínico que tem sido invocado. Ao passo que os acidentes vasculares de origem arterial ocorrem sobretudo em pessoas de idade e são constituídos pela trombose cerebral, a hemorragia ocorre 
em indivíduos novos nos quais as artérias mantêm ainda a sua capacidade defensiva.

Assim, em face dêsses sucessivos argumentos, a dúvida subsiste hoje sôbre se a hemorragia cerebral é primitivamente de origem arterial ou venosa. Scheinker tem tentado demonstrar histològicamente esta última origem com aspectos de estase e dilatação venosa a que chama venoporose e venoparalisia, que encontra nas proximidades dos focos hemorrágicos.

Outra ordem de factos que pretendemos encarar e que tem suma importância para a patogenia da hemorragia cerebral, é a que se refere à existência prévia de alterações parenquimatosas.

Referi-me já à opinião de Rosenblatt, que admite que as alterações vasculares serão vindas, não do interior do vaso, mas dum parênquima cerebral alterado por sucessivas perturbações da sua irrigação. Vários outros trabalhos experimentais têm conseguido demonstrar que efectivamente uma alteração do parênquima cerebral, consecutiva às modificações vasomotoras, parece desempenhar papel importante na patogenia do insulto hemorrágico.

Qual seria a substância produzida ao nível do parênquima que iria colaborar na produção das alterações vasculares? Várias têm sido apontadas, desde o ácido láctico de que falava Westphal, à substância corrosiva encontrada por Fisher Wäsels no macerado cerebral dos hipertónicos, e à acidez do parênquima cerebral proporcional à taxa de glicemia, encontrada por Holmes e Shiff.

Em qualquer caso, a substância existente para qualquer das doutrinas que venho de citar, seria sempre uma resultante da falta de oxigénio. Seriam as sucessivas vasoconstriç̧ões ocorridas ao nível da circulação que teriam como conseqüência a produção de substâncias nocivas, resultantes da insuficiente oxigenação. Este facto é fundamental na nossa concepção actual da patogenia da hemorragia cerebral e a explicação mais lógica da sede preferencial dêste processo.

Chegamos, assim, ao conceito actual da patogenia da hemorragia cerebral, conceito no qual os fenómenos funcionais têm um papel fundamental.

Partimos da noção da hipertensão arterial filiada a uma constituição morfológica especial. Esta hipertensão arterial seria a causa de espasmos arteriais repetidos, os quais freqüentemente se propagariam às veias. Os territórios irrigados por êstes vasos seriam submetidos a sucessivos fenómenos de isquemia; certos dêles, especialmente sensíveis à carência de oxigénio, em relação possível com o seu conteúdo em ferro, seriam sede de alterações precoces que se repercutiriam sôbre os próprios vasos. Desta sucessão de variaçóes funcionais, e desta acção exterior da noxa provinda da alteração parenquimatosa, surgiria uma nova série de estimulos causadores de novas estases, com alterações terminais das paredes e, por fim, diapedese maciça e talvez "rhexis" das artérias ou das veias, causadora final da própria hemorragia. 
Entretanto, alguns problemas subsistem. Um dêles não pode ser passado em claro: o da subitaneidade do quadro clínico.

Acabamos de ver que a hemorragia cerebral não é um fenómeno brusco; é antes o epílogo duma série de alterações que se vêm passando de longa data ao nível da circulação e do parênquima do cérebro. Como explicar então êste epílogo catastrófico? Como explicar que o quadro clínico manifeste exclusivamente nesta altura precisa a hemorragia, e não antes? Esta dúvida tem sido um dos graves obstáculos a tôdas as tentativas de explicação da patogenia da hemorragia cerebral.

Pessoalmente, suponho que o quadro clínico da apoplexia cerebral, pela sua semelhança com quadros doutro género, surgidos após os traumatismos cranianos (o quadro da comoção cerebral) ou após os ataques epilépticos (o quadro do coma pós-comicial), deve ter uma provável origem hipotalâmica. Julgo que o quadro da apoplexia faz parte das formas gerais da reacção encefálica. $O$ seu aparecimento é condicionado por um limiar de desencadeamento. Esse limiar é atingido apenas a certa altura e, como sucede após a epilepsia ou após o traumatismo craniano, o quadro do coma segue a lei do tudo ou nada; aparece bruscamente, manifesta-se sùbitamente com todo o seu aparato clínico, que constitui, no so presente, a apoplexia. Não que a hemorragia tenha sido brusca; ela é a resultante duma longa série de fenómenos que podem ocorrer durante muitos dias ou semanas; o que tem carácter brusco é o quadro apoplético, justamente porque êle traduz o sofrimento agudo da região até então não interessada no fenómeno.

Seja como fôr, o que fica demonstrado é que o sistema vasomotor desempenha papel de primeira plana na patogenia da hemorragia cerebral. Não iremos até ao extremo de Schwartz, que considerava a apoplexia hipertónica, isto é, a hemorragia cerebral, como um fenómeno puramente funcional, em oposição à arteriosclerótica ou à embólica, que seriam principalmente orgânicas. Entretanto, não se pode deixar de salientar a importância fundamental do papel funcional na patogenia dêste fenómeno.

Ocupar-me-ei seguidamente do diagnóstico diferencial da hemorragia cerebral.

A própria evolução da terapêutica tornou premente a necessidade dum diagnóstico diferencial rigoroso entre as várias causas de insulto apoplético, sobretudo entre a hemorragia e a trombose cerebral. Com efeito, foram-se desenvolvendo, tanto para a trombose como para a embolia, uma série de novas terapêuticas que vão desde o bloqueio do simpático cervical, por infiltração do estrelado, até os anticoagulantes como o tromexan ou a heparina, terapêuticas estas cuja aplicação pode ser fatal nos casos de hemorragia cerebral. O mesmo ocorre com os vasodilatadores, sobretudo com os enérgicos dilatadores do grupo nicotínico, que estudamos detalhadamente e lançamos na terapêutica, e que, aplicados em casos de hemorragia cerebral, podem dar lugar a resultados funestos. 


\section{Elementos de diagnóstico}

Freqüuencia dos ictos anteriores

Idade de maior freqüência

Sintomas anteriores de arteriosclerose cerebral

Sintomas cardiovasculares

\section{Pressão arterial}

Horário do aparecimento do icto

Perda do conhecimento

Fenómenos convulsivos

Cefaléias, vómitos

Cheyne-Stokes e outros ritmos respiratórios anormais

Lesões focais cerebrais

Lesōes dos nervos cranianos

Desvio conjugado da cabeça e dos olhos

Quadriplegia

Babinsky bilateral

Sindrome meníngea; líquor hemorrágico

Bilirrubinemia

Morte

\section{Raros}

Hipertensão

Mx. $20-$ Mn. 11

(média de 30 casos)

Diurno (esforços)

Imediata

Pouco freqüentes generalizados $14 \%$

Muito freqüente

Possiveis

(inundação ventricular)

Freqüentes $50 \%$

Aumentada $0,5 \mathrm{mg}$

Freqüentemente precoce: $1 .^{0}-30^{\circ}$ dia. Causa central

\begin{tabular}{|c|c|c|c|c|}
\hline Elementos de diagnóstico & Hemorragia cerebral & Embolia cerebral & Trombose cerebral & Hemorragia meníngea \\
\hline Freqüência dos ictos anteriores & Possiveis & Raros & Muito freqüentes & Raros \\
\hline Idade de maior freqüência & Cêrca dos 55 anos & $30-50$ & Após os 65 & Tôdas as idades \\
\hline $\begin{array}{c}\text { Sintomas anteriores de arterios- } \\
\text { clerose cerebral }\end{array}$ & Raros & Nulos & Muito freqüenlıs & Nulos \\
\hline Sintomas cardiovasculares & Raros & $\begin{array}{l}\text { I.esño valvular, fibrilasão. } \\
\text { aortite, } \\
\begin{array}{c}\text { enfarte } \\
\text { sépsis. }\end{array}\end{array}$ & $\begin{array}{l}\text { Cardiosclerose e arterios- } \\
\text { clerose generalizada }\end{array}$ & Nulos \\
\hline Pressão arterial & $\begin{array}{l}\text { Hipertensão } \\
\text { Mx. } 20-\text { Mn. } 11 \\
\text { (média de } 30 \text { casos) }\end{array}$ & Normal & Moderadamente elevada & Normal \\
\hline Horário do aparecimento do icto & Diurno (esforços) & Diurno & Noturno & Diurno (esforços) \\
\hline Perda do conhecimento & Imediata & Imediata & Lentamente progressiva & $\begin{array}{c}\text { Progressiva e em geral } \\
\text { incompleta }\end{array}$ \\
\hline Fenómenos convulsivos & $\begin{array}{l}\text { Pouco freqüientes } \\
\text { generalizados } 1+\%\end{array}$ & Raros, focais $7 \%$ & $\begin{array}{l}\text { Muito freqüentes, fociis } \\
\text { ou generalizados } 30 \%\end{array}$ & Raros \\
\hline Cefaléias, vómitos & Freqüentes & Faltam & Raros & Frequientes \\
\hline $\begin{array}{c}\text { Cheyne-Stokes e outros ritmos } \\
\text { respiratórios anormais }\end{array}$ & Freqüentes & Raros & Raros & Pouco freqüientes \\
\hline Lesões focais cerebrais & Constantes & Muito freqüentes & Muito freqüentes & Raras \\
\hline Lesōes dos nervos cranianos & Raras & Faltam & Faltam & Freqüentes (III par) \\
\hline $\begin{array}{l}\text { Desvio conjugado da cabeça e } \\
\text { dos olhos }\end{array}$ & Muito freqüente & Raro & Pouco freqüente & Raro \\
\hline $\begin{array}{c}\text { Quadriplegia } \\
\text { Babinsky bilateral }\end{array}$ & $\begin{array}{l}\text { Possiveis } \\
\text { (inundação ventricular) }\end{array}$ & Faltam & Faltain & Raros \\
\hline $\begin{array}{c}\text { Síndrome meníngea; líquor } \\
\text { hemorrágico }\end{array}$ & Freqüientes $50 \%$ & Faltam & Faltam & Constantes \\
\hline Bilirrubinemia & Aumentada $0,5 \mathrm{mg}$ & Normal $=0,5 \mathrm{mg}$ & Normal $=0,5 \mathrm{mg}$ & Aumentada $0,5 \mathrm{mgr}$ \\
\hline Morte & $\begin{array}{l}\text { Freqüentemente precoce: } \\
1.0^{0}-0^{\circ} \text { dia. Causa central }\end{array}$ & $\begin{array}{l}\text { Tardia }-8.0 \text { dia } \\
\text { complicaçôes }\end{array}$ & $\begin{array}{l}\text { Tardia }-5.0 \text { dia } \\
\quad \text { complicaçồes }\end{array}$ & $\begin{array}{l}\text { Freqüentemente precoce, } \\
1.0 .3 .^{\circ} \text { dia causa central }\end{array}$ \\
\hline
\end{tabular}

\begin{tabular}{|c|c|c|c|c|}
\hline Elementos de diagnóstico & Hemorragia cerebral & Embolia cerebral & Trombose cerebral & Hemorragia meníngea \\
\hline Freqüência dos ictos anteriores & Possiveis & Raros & Muito frequientes & Raros \\
\hline Idade de maior freqüência & Cêrca dos 55 anos & $30-50$ & Após os 65 & Tôdas as idades \\
\hline $\begin{array}{c}\text { Sintomas anteriores de arterios- } \\
\text { clerose cerebral }\end{array}$ & Raros & Nulos & Muito freqüenl.ss & Nulos \\
\hline Sintomas cardiovasculares & Raros & $\begin{array}{l}\text { I.esño valvular, fibrilasão. } \\
\text { aortite, } \\
\begin{array}{l}\text { enfarte } \\
\text { sépsis. }\end{array}\end{array}$ & $\begin{array}{l}\text { Cardiosclerose e arterios- } \\
\text { clerose gencralizada }\end{array}$ & Nulos \\
\hline Pressão arterial & $\begin{array}{l}\text { Hipertensão } \\
\text { Mx. } 20-\text { Mn. } 11 \\
\text { (média de } 30 \text { casos) }\end{array}$ & Normal & Moderadamente elevada & Normal \\
\hline Horário do aparecimento do icto & Diurno (esforços) & Diurno & Noturno & Diurno (esforços) \\
\hline Perda do conhecimento & Imediata & Imediata & Lentamente progressiva & $\begin{array}{c}\text { Progressiva e em geral } \\
\text { incompleta }\end{array}$ \\
\hline Fenómenos convulsivos & $\begin{array}{l}\text { Pouco freqüientes } \\
\text { generalizados } 1+\%\end{array}$ & Raros, focais $7 \%$ & $\begin{array}{l}\text { Muito freqüentes, focuis } \\
\text { ou generalizados } 30 \%\end{array}$ & Raros \\
\hline Cefaléias, vómitos & Freqüentes & Faltam & Raros & Frequientes \\
\hline $\begin{array}{c}\text { Cheyne-Stokes e outros ritmos } \\
\text { respiratórios anormais }\end{array}$ & Freqüentes & Raros & Raros & Pouco frequientes \\
\hline Lesões focais cerebrais & Constantes & Muito freqüentes & Muito frequientes & Raras \\
\hline Lesōes dos nervos cranianos & Raras & Faltam & Faltam & Freqüentes (III par) \\
\hline $\begin{array}{c}\text { Desvio conjugado da cabeça e } \\
\text { dos olhos }\end{array}$ & Muito freqüente & Raro & Pouco freqüente & Raro \\
\hline $\begin{array}{c}\text { Quadriplegia } \\
\text { Babinsky bilateral }\end{array}$ & $\begin{array}{l}\text { Possiveis } \\
\text { (inundação ventricular) }\end{array}$ & Faltam & Faltain & Raros \\
\hline $\begin{array}{c}\text { Sindrome meníngea; liquor } \\
\text { hemorrágico }\end{array}$ & Freqüentes $50 \%$ & Faltam & Faltam & Constantes \\
\hline Bilirrubinemia & Aumentada $0,5 \mathrm{mg}$ & Normal $=0,5 \mathrm{mg}$ & Normal $=0,5 \mathrm{mg}$ & Aumentada $0,5 \mathrm{mgr}$ \\
\hline Morte & $\begin{array}{l}\text { Freqüentemente precoce: } \\
1 .^{0}-30^{\circ} \text { dia. Causa central }\end{array}$ & $\begin{array}{l}\text { Tardia }-1 . .^{\circ} \text { dia } \\
\text { complicações }\end{array}$ & $\begin{array}{l}\text { Tardia } \\
\text { complicações }\end{array}$ & $\begin{array}{l}\text { Frequientemente precoce, } \\
1.0 .3 .^{\circ} \text { dia causa central }\end{array}$ \\
\hline
\end{tabular}

Trombose cerebral

Normal

Diurno

Imediata

Raros, focais $7 \%$

Faltam

Faltam

Faltam

Normal $=0,5 \mathrm{mg}$

Tardia - 8.0 dia complicações

Lentamente progressiva

\begin{tabular}{|c|c|c|c|c|}
\hline Elementos de diagnóstico & Hemorragia cerebral & Embolia cerebral & Trombose cerebral & Hemorragia meníngea \\
\hline Freqüência dos ictos anteriores & Possíveis & Raros & Muito freqüentes & Raros \\
\hline Idade de maior freqüência & Cêrca dos 55 anos & $30-50$ & Após os 65 & Tôdas as idades \\
\hline $\begin{array}{c}\text { Sintomas anteriores de arterios- } \\
\text { clerose cerebral }\end{array}$ & Raros & Nulos & Muito freqüenl.ss & Nulos \\
\hline Sintomas cardiovasculares & Raros & $\begin{array}{l}\text { I.esño valvular, fibrilasão. } \\
\text { aortite, enfarte recente, } \\
\text { sépsis. }\end{array}$ & $\begin{array}{l}\text { Cardiosclerose e arterios- } \\
\text { clerose generalizada }\end{array}$ & Nulos \\
\hline Pressão arterial & $\begin{array}{l}\text { Hipertensão } \\
\text { Mx. } 20-M n .11 \\
\text { (média de } 30 \text { casos) }\end{array}$ & Normal & Moderadamente elevada & Normal \\
\hline Horário do aparecimento do icto & Diurno (esforços) & Diurno & Noturno & Diurno (esforços) \\
\hline Perda do conhecimento & Imediata & Imediata & Lentamente progressiva & $\begin{array}{c}\text { Progressiva e em geral } \\
\text { incompleta }\end{array}$ \\
\hline Fenómenos convulsivos & $\begin{array}{l}\text { Pouco frequientes } \\
\text { generalizados } 1+\%\end{array}$ & Raros, focais $7 \%$ & $\begin{array}{l}\text { Muito freqüentes, focais } \\
\text { ou generalizados } 30 \%\end{array}$ & Raros \\
\hline Cefaléias, vómitos & Freqüentes & Faltam & Raros & Frequientes \\
\hline $\begin{array}{c}\text { Cheyne-Stokes e outros ritmos } \\
\text { respiratórios anormais }\end{array}$ & Freqüentes & Raros & Raros & Pouco frequientes \\
\hline Lesões focais cerebrais & Constantes & Muito freqüentes & Muito freqüentes & Raras \\
\hline Lesōes dos nervos cranianos & Raras & Faltam & Faltam & Freqüentes (III par) \\
\hline $\begin{array}{l}\text { Desvio conjugado da cabeça e } \\
\text { dos olhos }\end{array}$ & Muito freqüente & Raro & Pouco freqüente & Raro \\
\hline $\begin{array}{c}\text { Quadriplegia } \\
\text { Babinsky bilateral }\end{array}$ & $\begin{array}{c}\text { Possiveis } \\
\text { (inundação ventricular) }\end{array}$ & Faltam & Faltain & Raros \\
\hline $\begin{array}{l}\text { Sindrome meníngea; liquor } \\
\text { hemorrágico }\end{array}$ & Freqüentes $50 \%$ & Faltam & Faltam & Constantes \\
\hline Bilirrubinemia & Aumentada $0,5 \mathrm{mg}$ & Normal $=0,5 \mathrm{mg}$ & Normal $=0,5 \mathrm{mg}$ & Aumentada $0,5 \mathrm{mgr}$ \\
\hline Morte & $\begin{array}{l}\text { Freqüentemente precoce: } \\
1.0-30^{\circ} \text { dia. Causa central }\end{array}$ & $\begin{array}{l}\text { Tardia }-1 . .^{\circ} \text { dia } \\
\text { complicaçôes }\end{array}$ & $\begin{array}{l}\text { Tardia } \underset{\text { complicaçōes }}{5.0} \text { dia } \\
\text { com }\end{array}$ & $\begin{array}{l}\text { Freqüentemente precoce, } \\
1.0 .3 .0 \text { dia causa central }\end{array}$ \\
\hline
\end{tabular}

\begin{tabular}{|c|c|c|c|c|}
\hline Elementos de diagnóstico & Hemorragia cerebral & Embolia cerebral & Trombose cerebral & Hemorragia meníngea \\
\hline Freqüência dos ictos anteriores & Possiveis & Raros & Muito frequientes & Raros \\
\hline Idade de maior freqüência & Cêrca dos 55 anos & $30-50$ & Após os 65 & Tôdas as idades \\
\hline $\begin{array}{c}\text { Sintomas anteriores de arterios- } \\
\text { clerose cerebral }\end{array}$ & Raros & Nulos & Muito freqüenl.ss & Nulos \\
\hline Sintomas cardiovasculares & Raros & $\begin{array}{l}\text { I.esño valvular, fibrilasão. } \\
\text { aortite, } \\
\begin{array}{l}\text { enfarte } \\
\text { sépsis. }\end{array}\end{array}$ & $\begin{array}{l}\text { Cardiosclerose e arterios- } \\
\text { clerose gencralizada }\end{array}$ & Nulos \\
\hline Pressão arterial & $\begin{array}{l}\text { Hipertensão } \\
\text { Mx. } 20-\text { Mn. } 11 \\
\text { (média de } 30 \text { casos) }\end{array}$ & Normal & Moderadamente elevada & Normal \\
\hline Horário do aparecimento do icto & Diurno (esforços) & Diurno & Noturno & Diurno (esforços) \\
\hline Perda do conhecimento & Imediata & Imediata & Lentamente progressiva & $\begin{array}{c}\text { Progressiva e em geral } \\
\text { incompleta }\end{array}$ \\
\hline Fenómenos convulsivos & $\begin{array}{l}\text { Pouco freqüientes } \\
\text { generalizados } 1+\%\end{array}$ & Raros, focais $7 \%$ & $\begin{array}{l}\text { Muito freqüentes, focuis } \\
\text { ou generalizados } 30 \%\end{array}$ & Raros \\
\hline Cefaléias, vómitos & Freqüentes & Faltam & Raros & Frequientes \\
\hline $\begin{array}{c}\text { Cheyne-Stokes e outros ritmos } \\
\text { respiratórios anormais }\end{array}$ & Freqüentes & Raros & Raros & Pouco frequientes \\
\hline Lesões focais cerebrais & Constantes & Muito freqüentes & Muito frequientes & Raras \\
\hline Lesōes dos nervos cranianos & Raras & Faltam & Faltam & Freqüentes (III par) \\
\hline $\begin{array}{c}\text { Desvio conjugado da cabeça e } \\
\text { dos olhos }\end{array}$ & Muito freqüente & Raro & Pouco freqüente & Raro \\
\hline $\begin{array}{c}\text { Quadriplegia } \\
\text { Babinsky bilateral }\end{array}$ & $\begin{array}{l}\text { Possiveis } \\
\text { (inundação ventricular) }\end{array}$ & Faltam & Faltain & Raros \\
\hline $\begin{array}{c}\text { Sindrome meníngea; liquor } \\
\text { hemorrágico }\end{array}$ & Freqüentes $50 \%$ & Faltam & Faltam & Constantes \\
\hline Bilirrubinemia & Aumentada $0,5 \mathrm{mg}$ & Normal $=0,5 \mathrm{mg}$ & Normal $=0,5 \mathrm{mg}$ & Aumentada $0,5 \mathrm{mgr}$ \\
\hline Morte & $\begin{array}{l}\text { Freqüentemente precoce: } \\
1 .^{0}-30^{\circ} \text { dia. Causa central }\end{array}$ & $\begin{array}{l}\text { Tardia }-1 . .^{\circ} \text { dia } \\
\text { complicações }\end{array}$ & $\begin{array}{l}\text { Tardia } \\
\text { complicações }\end{array}$ & $\begin{array}{l}\text { Frequientemente precoce, } \\
1.0 .3 .^{\circ} \text { dia causa central }\end{array}$ \\
\hline
\end{tabular}

\begin{tabular}{|c|c|c|c|c|}
\hline Elementos de diagnóstico & Hemorragia cerebral & Embolia cerebral & Trombose cerebral & Hemorragia meníngea \\
\hline Freqüência dos ictos anteriores & Possiveis & Raros & Muito frequientes & Raros \\
\hline Idade de maior freqüência & Cêrca dos 55 anos & $30-50$ & Após os 65 & Tôdas as idades \\
\hline $\begin{array}{c}\text { Sintomas anteriores de arterios- } \\
\text { clerose cerebral }\end{array}$ & Raros & Nulos & Muito freqüenl.ss & Nulos \\
\hline Sintomas cardiovasculares & Raros & $\begin{array}{l}\text { I.esño valvular, fibrilasão. } \\
\text { aortite, } \\
\begin{array}{l}\text { enfarte } \\
\text { sépsis. }\end{array}\end{array}$ & $\begin{array}{l}\text { Cardiosclerose e arterios- } \\
\text { clerose gencralizada }\end{array}$ & Nulos \\
\hline Pressão arterial & $\begin{array}{l}\text { Hipertensão } \\
\text { Mx. } 20-\text { Mn. } 11 \\
\text { (média de } 30 \text { casos) }\end{array}$ & Normal & Moderadamente elevada & Normal \\
\hline Horário do aparecimento do icto & Diurno (esforços) & Diurno & Noturno & Diurno (esforços) \\
\hline Perda do conhecimento & Imediata & Imediata & Lentamente progressiva & $\begin{array}{c}\text { Progressiva e em geral } \\
\text { incompleta }\end{array}$ \\
\hline Fenómenos convulsivos & $\begin{array}{l}\text { Pouco freqüientes } \\
\text { generalizados } 1+\%\end{array}$ & Raros, focais $7 \%$ & $\begin{array}{l}\text { Muito freqüentes, focuis } \\
\text { ou generalizados } 30 \%\end{array}$ & Raros \\
\hline Cefaléias, vómitos & Freqüentes & Faltam & Raros & Frequientes \\
\hline $\begin{array}{c}\text { Cheyne-Stokes e outros ritmos } \\
\text { respiratórios anormais }\end{array}$ & Freqüentes & Raros & Raros & Pouco frequientes \\
\hline Lesões focais cerebrais & Constantes & Muito freqüentes & Muito frequientes & Raras \\
\hline Lesōes dos nervos cranianos & Raras & Faltam & Faltam & Freqüentes (III par) \\
\hline $\begin{array}{c}\text { Desvio conjugado da cabeça e } \\
\text { dos olhos }\end{array}$ & Muito freqüente & Raro & Pouco freqüente & Raro \\
\hline $\begin{array}{c}\text { Quadriplegia } \\
\text { Babinsky bilateral }\end{array}$ & $\begin{array}{l}\text { Possiveis } \\
\text { (inundação ventricular) }\end{array}$ & Faltam & Faltain & Raros \\
\hline $\begin{array}{c}\text { Sindrome meníngea; liquor } \\
\text { hemorrágico }\end{array}$ & Freqüentes $50 \%$ & Faltam & Faltam & Constantes \\
\hline Bilirrubinemia & Aumentada $0,5 \mathrm{mg}$ & Normal $=0,5 \mathrm{mg}$ & Normal $=0,5 \mathrm{mg}$ & Aumentada $0,5 \mathrm{mgr}$ \\
\hline Morte & $\begin{array}{l}\text { Freqüentemente precoce: } \\
1 .^{0}-30^{\circ} \text { dia. Causa central }\end{array}$ & $\begin{array}{l}\text { Tardia }-1 . .^{\circ} \text { dia } \\
\text { complicações }\end{array}$ & $\begin{array}{l}\text { Tardia } \\
\text { complicações }\end{array}$ & $\begin{array}{l}\text { Frequientemente precoce, } \\
1.0 .3 .^{\circ} \text { dia causa central }\end{array}$ \\
\hline
\end{tabular}

\section{Hemorragia meníngea}

Raros

Tôdas as idades

Nulos

Nulos

Normal

Diurno (esforços)

Muito freqüentes, focais ou generalizados $30 \%$

Raros

Muito frequientes

Faltam

Pouco freqüiente

Faltain

Faltam

Normal $=0,5 \mathrm{mg}$

Tardia - $5 .^{\circ}$ dia complicações
Progressiva e em geral incompleta

Raros

\section{Frequientes}

Pouco frequientes

Raras

Raro

Raros

Constantes

Aumentada $0,5 \mathrm{mgr}$

Frequientemente precoce, 1.0.3.0 dia causa central
Freqüentes (III par)

\begin{tabular}{|c|c|c|c|c|}
\hline Elementos de diagnóstico & Hemorragia cerebral & Embolia cerebral & Trombose cerebral & Hemorragia meníngea \\
\hline Freqüência dos ictos anteriores & Possiveis & Raros & Muito frequientes & Raros \\
\hline Idade de maior freqüência & Cêrca dos 55 anos & $30-50$ & Após os 65 & Tôdas as idades \\
\hline $\begin{array}{c}\text { Sintomas anteriores de arterios- } \\
\text { clerose cerebral }\end{array}$ & Raros & Nulos & Muito freqüenl.ss & Nulos \\
\hline Sintomas cardiovasculares & Raros & $\begin{array}{l}\text { I.esño valvular, fibrilasão. } \\
\text { aortite, } \\
\begin{array}{l}\text { enfarte } \\
\text { sépsis. }\end{array}\end{array}$ & $\begin{array}{l}\text { Cardiosclerose e arterios- } \\
\text { clerose gencralizada }\end{array}$ & Nulos \\
\hline Pressão arterial & $\begin{array}{l}\text { Hipertensão } \\
\text { Mx. } 20-\text { Mn. } 11 \\
\text { (média de } 30 \text { casos) }\end{array}$ & Normal & Moderadamente elevada & Normal \\
\hline Horário do aparecimento do icto & Diurno (esforços) & Diurno & Noturno & Diurno (esforços) \\
\hline Perda do conhecimento & Imediata & Imediata & Lentamente progressiva & $\begin{array}{c}\text { Progressiva e em geral } \\
\text { incompleta }\end{array}$ \\
\hline Fenómenos convulsivos & $\begin{array}{l}\text { Pouco freqüientes } \\
\text { generalizados } 1+\%\end{array}$ & Raros, focais $7 \%$ & $\begin{array}{l}\text { Muito freqüentes, focuis } \\
\text { ou generalizados } 30 \%\end{array}$ & Raros \\
\hline Cefaléias, vómitos & Freqüentes & Faltam & Raros & Frequientes \\
\hline $\begin{array}{c}\text { Cheyne-Stokes e outros ritmos } \\
\text { respiratórios anormais }\end{array}$ & Freqüentes & Raros & Raros & Pouco frequientes \\
\hline Lesões focais cerebrais & Constantes & Muito freqüentes & Muito frequientes & Raras \\
\hline Lesōes dos nervos cranianos & Raras & Faltam & Faltam & Freqüentes (III par) \\
\hline $\begin{array}{c}\text { Desvio conjugado da cabeça e } \\
\text { dos olhos }\end{array}$ & Muito freqüente & Raro & Pouco freqüente & Raro \\
\hline $\begin{array}{c}\text { Quadriplegia } \\
\text { Babinsky bilateral }\end{array}$ & $\begin{array}{l}\text { Possiveis } \\
\text { (inundação ventricular) }\end{array}$ & Faltam & Faltain & Raros \\
\hline $\begin{array}{c}\text { Sindrome meníngea; liquor } \\
\text { hemorrágico }\end{array}$ & Freqüentes $50 \%$ & Faltam & Faltam & Constantes \\
\hline Bilirrubinemia & Aumentada $0,5 \mathrm{mg}$ & Normal $=0,5 \mathrm{mg}$ & Normal $=0,5 \mathrm{mg}$ & Aumentada $0,5 \mathrm{mgr}$ \\
\hline Morte & $\begin{array}{l}\text { Freqüentemente precoce: } \\
1 .^{0}-30^{\circ} \text { dia. Causa central }\end{array}$ & $\begin{array}{l}\text { Tardia }-1 . .^{\circ} \text { dia } \\
\text { complicações }\end{array}$ & $\begin{array}{l}\text { Tardia } \\
\text { complicações }\end{array}$ & $\begin{array}{l}\text { Frequientemente precoce, } \\
1.0 .3 .^{\circ} \text { dia causa central }\end{array}$ \\
\hline
\end{tabular}


Não me referirei em detalhe ao diagnóstico clínico porque para tal me não chegaria o tempo. $O$ quadro junto salienta, dentro do possível, os principais elementos dêste diagnóstico, incluindo nêle não apenas a hemorragia, o amolecimento ou a embolia, como ainda a hemorragia meníngea, resultante freqüente da rotura dos aneurismas e freqüente causadora de acidentes ictiformes. referir.

Há, porém, alguns detalhes de interêsse mais actual que pretendo

Encontra-se mencionado no quadro acima o valor da bilirrubinemia para o diagnóstico diferencial. Wilder já ensaiara o doseamento da bilirrubinemia sangüínea nas hemorragias cerebrais, mas o método caiu depois no esquecimento. Conhecedores do facto e dispondo hoje de técnicas mais rigorosas, com o nosso colaborador Vasco Chichorro, levamos a efeito uma série de investigações no sentido de apurar o valor do doseamento da bilirrubinemia no diagnóstico das hemorragias cerebrais. 0 fundamento do método é simples: na hemorragia cerebral, como em tôdas as hemorragias, há transformação do pigmento hemático, passando por diversas fases, primeiro em biliverdina depois em hematoidina. Os trabalhos de Eppinger e, mais tarde, os de bioquímicos americanos mostraram que esta transformação, fundamento da teoria de bilirrubinogénese extra-hepática, conduz à formação de bilirrubina, visto que a biliverdina é um antecessor da bilirrubina e a hematoidina é a própria bilirrubina, originada fora do fígado. Assim, o teor de bilirrubina deveria ser elevado nos casos de hemorragia cerebral e tudo estava em saber quando começava essa elevação, visto que só a precocidade teria interêsse diagnóstico. Foi nesse sentido que se dirigiram as nossas investigações. Sabendo que a bilirrubinemia normal é de 0,3 a $0,5 \mathrm{mg} / 100 \mathrm{ml}$, verificamos que em $95 \%$ das hemorragias cerebrais se encontram valores elevados, chegando a atingir 3 e $4 \mathrm{mg}$. $O$ mesmo se verifica nas hemorragias meníngeas, dando-se o contrário nas tromboses e nas embolias, nas quais apenas 10 a $20 \%$ dos casos apresenta alteração da bilirrubinemia. Valores elevados da bilirrubinemia aparecem nas hemorragias, segundo a nossa experiência, já ao fim de duas horas após o acidente e esta circunstância atribui ao método bastante valor diagnóstico.

Outro lado a que me quero referir é o do electrencefalograma. Temos praticado, como muitos outros autores, electrencefalogramas sistemàticamente em casos de acidente vascular cerebral, verificando que, quando êste acidente atinge a corticalidade cerebral, eventualidade muito freqüente, dá origem ao aparecimento de focos paroxísticos de ondas $\delta$ de tipo polimorfo e na região correspondente; a evolução regressiva dêstes focos permite distinguí-los dos focos produzidos por tumores. Pelo contrário, se a sede do acidente vascular foi profunda, não aparece, em regra, modificação do ritmo cerebral ou, quando muito, nota-se apenas o seu achata. mento. A persistência dum ritmo $\delta$ polimorfo num caso de acidente cerebral durante algum tempo, deixa sempre margem à esperança duma re- 
gressão: ao que parece, existe certa proporcionalidade entre a regressão clínica e a regressão electrencefalográfica do foco $\delta$, quando êste existe.

Quero ainda referir-se ao valor da angiografia. E' evidente que a angiografia é contra-indicada nos grandes hipertensos, com acidente apoplético agudo. Mas, quando se trata duma apoplexia progressiva e quando a tensão arterial não seja muito elevada, a possibilidade de formação dum hematoma intracerebral, e até a possibilidade de um êrro de diagnóstice numa hemorragia consecutiva a um aneurisma, leva a aconselhar a angiografia. Têmo-la praticado bastas vêzes em casos dêste género e devemos-lhe alguns sucessos de indicação operatória.

Tem-se também salientado, ùltimamente e sobretudo por Scott, o valor da radiografia do crânio mostrando desvios quanto à situação da pineal, quando esta esteja calcificada; não temos encontrado grande valor neste sinal.

Assim, com as indicações clínicas que se encontram resumidas no quadro acima exposto, ajudados pela dosagem do teor da bilirrubinemia, do traçado electrencefalográfico e, em casos especiais, da angiografia, poderemos, na maior parte dos casos, estabelecer, com relativo rigor, o diagnóstico de hemorragia cerebral.

Estamos agora em condições de abordar o que diz respeito à terapêutica da hemorragia cerebral. Falemos, em primeiro lugar e ràpidamente, da sua profilaxia, porque a profilaxia da hemorragia cerebral é afinal a terapêutica da hipertonia essencial e esta terapêutica encontra-se actualmente em plena evolução.

Importa, em primeiro lugar, diagnosticar a hipertonia precocemente. Há sempre que ter em atençâo os factôres constitucionais, a hereditariedade e a idade do seu aparecimento, factôres êstes que levarão a suspeitar da existência duma hipertensão arterial e a proceder às freqüentes e necessárias medidas da tensão.

Não insistiremos sôbre os sintomas precoces que indicam a sua existência (os sintomas não são mais do que os próprios pródromos da hemorragia cerebral). Volhard resume a terapêutica profilática em duas palavras gregas: "askese" para a terapêutica somática e "flegma" para a terapêutica psíquica. Um ascetismo rigoroso nos hábitos e uma calma imperturbável nos espíritos. Como executar êstes princípios?

Em primeiro lugar, pela dieta, que constitui, talvez ainda hoje, o principal elemento da terapêutica somática; seu efeito soberano é bem visível nas nefrites, na eclâmpsia, nas hipertensões graves. $\mathrm{O}$ primeiro princípio dietético é a restrição de sal. A dificuldade de execução desta dieta descloretada é grande, pois muitos doentes que na sua melhor boa fé se põem a fazer dieta descloretada, ingerem na realidade quantidades nocivas de cloreto de sódio. Usamos, para evitar êstes erros tão freqüentes, um processo simples que nos permitimos aconselhar: o do doseamento freqüente dos cloretos urinários, pois tôda a eliminação de cloretos superior a 5 gramas, implica numa dieta incorrectamente estabelecida. Além da 
redução de sal é de capital importância a redução da quantidade de líquiido: supressão de líqüidos às refeições, dieta quanto possível sêca.

Conforme diz Volhard, esta dieta sem sal e quase sem líqüidos é por excelência a dieta protectora do coração e dos vasos; a redução de proteínas (proibição de carne e peixe) em que tantos clínicos insistem, não tem senão interêsse relativo. De acôrdo com Volhard, permitimos a ingestão duma quantidade razoável de tais alimentos. Proibimos, sim, o café, o álcool e, na medida do possível, o tabaco, pelas variações tensionais que provocam e que predispõem para os acidentes vasculares. $O$ valor de certas dietas absolutas, como por exemplo a dieta de arroz, parece ser real mas o sacrifício que tais dietas exigem dos doentes ultrapassa, por via de regra, aquilo que nos é permitido impor-lhes.

Muitas medicações hipotensoras foram propostas, desde os vasodilatadores (nitritos, derivados de colina e do ácido nicotínico) até aos sulfocianatos, e a outras substâncias às quais se não podia atribuir real valor. A questão modificou-se sensivelmente nos últimos anos com as intervenções sôbre o simpático e o emprêgo de substâncias que sôbre êste actuam.

Não discutirei aqui o problema complexo do valor das ressecções do simpático no tratamento da hipertonia. Como é sabido, em certos países, sobretudo nos Estados Unidos, estas ressecções do tipo Smithwick, indo em larga extensão desde os primeiros gânglios dorsais até ao final da cadeia lombar ou em extensóes mais reduzidas, atingindo os últimos gânglios dorsais e o sistema esplâncnico, têm sido feitas em tal escala que em poucos anos se apresentam estatísticas de centenas de casos operados. A sua acção sôbre a tensão arterial é, na maior parte dos casos, evidente. Entretanto, um certo número, direi mesmo um número avultado de recaídas se têm apresentado. Além disso, noutros casos, a despeito da baixa da tensão, a evolução duma hipertonia benigna no sentido duma hipertonia maligna não foi evitada. A par disto, um certo número de complicações são de considèrar: estão neste caso a perda da potência genésica, bastante ireqüente, e as hipotensões ortostáticas, que inutilizam muitos doentes ou os forçam ao uso permanentes de aparelhos incômodos. Não temos grande experiência pessoal das gangliectomias, embora tenhamos feito praticar algumas. A nossa impressão, entretanto, não é favorável, já que se trata de uma intervenção de certo vulto e certo risco, e cujas conseqüências nocivas não são totalmente de pôr de parte.

Nos últimos anos, a medicação hipotensora encontrou alguns elementos valiosos; referimo-nos, sobretudo, aos derivados do metónio, ao cloreto de tetra-etil-amónio, ao hexametónio e a várias outras substâncias ganglioplégicas e simpaticolíticas que têm sido empregadas em larga escala. Temos experiência de algurnas delas, sobretudo do pendiomide, e os resultados que obtivemos sôbre a tensão, parecem-nos suficientemente favoráveis para nos levar a ahandonar, pelo menos por ora, o caminho operatório. E' possível, por intermédio dos ganglioplégicos e simpaticolíticos, do hexametónio ou do pendiomide, manter com tensões moderadas doen- 
tes portadores de hipertonias essenciais bastante acentuadas. $O$ valor real destas substâncias não nos deve fazer esquecer, não só o valor da dieta, mas também o valor de outras medicações. Estão neste caso as medicações protectoras da parede arterial: neste sentido nos últimos anos tem sido empregada largamente a rutina que, contrariando a acção da hialorudinase, permite aos vasos adquirir um melhor cimento intercelular das suas paredes. Temos empregado em larga escala a rutina no tratamento dos nossos hipertensos essenciais e temos dessa medicação uma impressão favorável.

Outra medicação cujo valor é incontestável na hipertensão essencial, é a sedativa. Conduzindo a menor excitabilidade nervosa e a maior calma psíquica, os sedativos trazem indirectamente benefício à hipertensão arterial. Assim, o luminal ou os seus derivados, os calmantes opiáceos e os sedativos do sistema nervoso vegetativo como os derivados da beladona e ergotamina, devem ser usados com os cuidados necessários o maior tempo possível. E', com efeito, da maior importância para o tratamento da hipertensão o sossêgo de espírito, a "flegma" de Volhard. Ao hipertenso devem ser proibidos os esforços, evitadas as preocupações, limitada a actividude intelectual ou profissional; as curas de águas, pelos repousos que implicam e pela maior facilidade de dietética, devem ser aconselhadas sem moderação. Também a actividade sexual deve ser sujeita a compreensivos conselhos, que lhe regulem a freqüência e limitem o esfôrço. 0 acto sexual é uma das grandes causas desencadeantes da hemorragia cerehral; são inúmeras as que vemos seguirem-se ao coito $e$, ainda recentemente, assistimos à morte de um indivíduo cuja terceira hemorragia cerebral fôra, como as anteriores, provocada pelo acto sexual. Não devemos esquecer ainda a possibilidade de que na génese da hipertonia essencial que temos ante os nossos olhos, possam existir factôres psíquicos de alto valor; uma psicoterapia adequada e mesmo, em certas eventualidades, o recurso à psicanálise, pode contribuir para reduzir sensivelmente uma hipertensão de causa psicógena.

Encaremos, agora, a terapêutica da própria hemorragia cerebral. São escassas as armas de que dispomos para combater êste tão grande mal. À parte o repouso em que imediatamente poremos o doente e os cuidados gerais, que são intuitivos, tais como evitar a asfixia pelos vómitos, evitar a formação precoce de escaras pela incontinência dos esfincteres, manter moderadamente elevada a cabeça do doente, etc., dividiremos a terapêutica em trệs partes: o tratamento da hipertensão craniana, o tratamento da situação cardiovascular e a terapêutica do foco hemorrágico pròpriamente dito.

Referimo-nos à hipertensão craniana que acompanha a hemorragia cerebral. A sua importância é enorme, visto que é o edema cerebral difuso e imediato, estabelecido em tôrno do foco, que mata o doente nas primeiras horas. Para contrariar esta hipertensão, empregamos as injecções endovenosas de sôro glicosado hipertónico, 30 a $40 \mathrm{ml}$, repetidos duas a três vêzes ao dia. A baixa de tensão produzida por estas injecções 
é transitória, mas têmo-la por extremamente benéfica nestes casos; produzem, além disso, aumento de diurese e fornecem ao doente algum alimento. A punçāo lombar é um péssimo meio descompressivo, que deve ser evitado; devemos limitar o seu uso às necessidades diagnósticas.

$\mathrm{Na}$ terapêutica da situação cardiovascular que a hemorragia envolve, encaremos em primeiro lugar a questão da sangria. Muito se tem discutido acêrca do valor da sangria; o seu emprêgo imediato estaria indicado na crise hipertensiva que acompanha a hemorragia cerebral. Sem nos podermos alargar, diremos entretanto que a origem de tal hipertensão paroxística nos parece antes central, conseqüência e não causa da hemorragia cerebral. Além disto, a sangria, provocando uma redução do volume do sangue, traz consigo uma contracção reflexa de todo o sistema cardiovascular. Daqui se infere que, em todos os casos em que não haja a certeza absoluta de se tratar de uma hemorragia, a sangria deve ser cautelosamente evitada. A contracção reflexa e a reducção circulatória que ela envolve, são seguramente nocivas e até fatais, no caso de se tratar de um amolecimento. Portanto, quanto mais velho fôr o doente e mais gradual o coma, tanto menos indicada estará a sangria. Esta, quando indicada, deverá orçar em regra, por 300 a $400 \mathrm{ml}$.

O meio mais preconizado para descarregar a circulação venosa cerebral voltou porém a ser, nos últimos anos, o emprêgo de sanguessugas. A deplecção sangüínea que fazem incide precisamente sôbre a circulação venosa cerebral, visto que às mastóides, onde elas estão aplicadas, afloram veias emissárias, comunicantes com a circulação endocraniana. Além disto, esta deplecção não é brusca e não resulta duma acção directa sôbre os vasos, evitando assim as acções reflexas provocadas pela sangria. Empregamos actualmente as sanguessugas em número de três ou quatro, repetidamente colocadas na mastóide, do lado do foco, de preferência.

O emprêgo de meios coagulantes (zimema, coaguleno, etc.) também divulgado nos últimos anos, é sem dúvida de utilidade. Nos casos em que existam análises positivas para sífilis, ou sintomas certos desta doença, o tratamento específico deve ser iniciado logo que o estado do doente o permita.

Uma referência ainda à alimentação do doente: a longa permanência em coma, sem alimento, é desfavorável para o doente; a acidose facilita as complicações pela diminuição da resistência. Costumamos, por isso, alimentar os doentes por sonda nasal, sempre que não haja intolerância gástrica, e com os cuidados que essa operação exige, administramos duas vêzes por dia sumo de laranja ou açúcar. Uma referência também à profilaxia das complicações infecciosas, tão freqüentes nestes estados; o uso sistemático de penicilina e da associação de penicilina-estreptomicina parece-nos de indicar com tôda a regularidade.

Ocupemo-nos, finalmente, da terapêutica pròpriamente dirigida contra o foco hemorrágico. A pouca eficácia dos recursos terapêuticos expostos, a importância da hipertensão intracraniana levaram naturalmente a pensar 
na possibilidade de uma terapêutica cirúrgica. A opinião actual dos clínicos de maior experiência neste capítulo não é concordante. Encontramos freqüentemente, na literatura, relações de casos cujos resultados são os mais animadores possíveis, como sucedia ainda há pouco tempo comı a série de 25 hemorragias cerebrais operadas, publicada por Michael Scott. Interrogados, porém, a maior parte dos neurocirurgiōes e consultando mesmo os resultados do nosso Serviço, vemos que a perspectiva não é animadora.

Há, em primeiro lugar, uma reserva a pôr a tôdas as estatísticas favoráveis publicadas: é a de que elas não dizem respeito, na maioria dos casos, a verdadeiras hemorragias cerebrais, mas sim a roturas de aneurismas, hemorragias intratumorais, e outras situações que não correspondem à verdadeira apoplexia hipertónica de que falamos. Nestes casos, é evidente que o esvaziamento do foco, a laqueação do aneurisma ou da própria carótida, ou a exerese do tumor, serão capazes de curar os doentes. Mas a situação é diferente na verdadeira hemorragia cerebral.

Outra reserva se deve ainda fazer: além da hemorragia cerebral a que chamaremos verdadeira, de sede putâmino-cápsulo-claustral, e génese hipertónica e vasomotora, existe uma outra forma de hemorragia, também intracerebral e espontânea, que consiste na aparição e desenvolvimento de uma colecção sangüínea fechada, verdadeiro hematoma intracerebral, em regra situado na substância branca, fora do lugar de eleição. A patogenia dêste hematoma intracerebral espontâneo não está esclarecida; se alguns casos correspondem a roturas de pequenos aneurismas periféricos ou a apoplexias de Bollinger, outras parecem ter a mesma patogenia que a apoplexia hipertónica. Nestes casos, a intervenção operatória oferece evidentes possibilidades de cura, em contraste com o que todos temos visto suceder na apoplexia clássica.

Assim, podemos resumir a nossa actual experiência, dizendo que a apoplexia hemorrágica maciça, de localização central, num portador de hipertonia, não põe, hoje pelo menos, um problema cirúrgico. Pelo contrárip, (1) se os sinais de hemorragia meníngea dominam os de hemorragia cerebral, (2) se a sintomatologia focal se agrava em lenta progressão (apoplexia ingravescens), (3) se os sintomas de hipertensão craniana são nítidos e tendem também a aumentar, (4) se a hipertensão arterial é escassa ou nula e se não há sinais claros de malignidade dessa hipertensão (retinopatia, cardiopatia ou nefropatia), a tentativa operatória deve ser considerada. Esta deve ser sistemàticamente precedida de radiografia simples (desvio da pineal?) e de angiografia. Sempre que sejam respeitados os postulados que pusemos, a angiografia percutânea é inócua e constitui um auxiliar de inestimável valor. Na verdadeira apoplexia hipertónica, porém, a cirurgia constitui uma possibilidade que se não deve por ora considerar. 